\title{
Characteristic and kinetics of corn stalk pyrolysis in a high pressure reactor and steam gasification of its char
}

\author{
Guojie Zhang ${ }^{\mathrm{a}, \mathrm{b}, *}$, Yinghui Sun ${ }^{\mathrm{a}}$, Yuliang Shi ${ }^{\mathrm{a}}$, Yong Jia ${ }^{\mathrm{a}}$, Ying Xu ${ }^{\mathrm{a}}$, Peiyu Zhao ${ }^{\mathrm{a}}$, \\ Yongfa Zhang a \\ a Key Laboratory of Coal Science and Technology, Ministry of Education and Shanxi Province, Taiyuan University of Technology, Taiyuan, PR China, 030024, \\ PR China \\ b State Key Laboratory of Coal and CBM Co-Mining, Jincheng, Shanxi, 048012, PR China
}

\section{A R T I C L E I N F O}

\section{Article history:}

Received 27 July 2016

Received in revised form

14 September 2016

Accepted 23 September 2016

Available online 28 September 2016

\section{Keywords:}

Corn stalk

Pyrolysis kinetics

Gasification

Characteristic

High pressure

\begin{abstract}
A B S T R A C T
Pyrolysis characteristics of the corn stalk were investigated at different temperatures and pressures, with focus mainly on the releasing profiles and forming behaviors of gas. The results show that a higher pressure was conducive to the yield of $\mathrm{H}_{2}$ and $\mathrm{CH}_{4}$, and was not conducive to the generation of CO. Combustible gas components increase with the increase temperature. $\mathrm{H}_{2}$ concentration was affected significantly by temperature, was mainly released at higher temperatures $\left(>500^{\circ} \mathrm{C}\right)$. At $700^{\circ} \mathrm{C}$, the combustible gas components are up to $90 \%$ and $\mathrm{H}_{2}$ concentration is up to $51.78 \%$. The gas components of corn stalk pyrolysis char steam gasification mainly consisted of $\mathrm{CO}$ and $\mathrm{H}_{2}, 25.7 \%$ and $50.7 \%$ respectively. The calorific value of gasification gas is up to $9508.9 \mathrm{~kJ} / \mathrm{M}^{3}$. A kinetic study of the pyrolysis process of the corn stalk was investigated using a thermogravimetric analyzer. As the heating rate increased, the activity energy reduced. By using the Popescu method to determine that shrinking core model can reflect the pyrolysis process of corn stalk truly at low temperature pyrolysis, and chemical reaction model can reflect the pyrolysis process of corn stalk truly at high temperature pyrolysis. Experimental results showed that values of kinetic parameters can be successfully used to understand the degradation mechanism of solid-state reaction.
\end{abstract}

(C) 2016 Elsevier B.V. All rights reserved.

\section{Introduction}

Resource and environmental problems have become major constraints for the rapid development of China. The renewable energy is an effective and alternative way to achieve the sustainable development of energy. Biomass is the only renewable energy which can be directly converted into carbon liquid and fuel gas $[1,2]$. It is derived from solar energy directly or indirectly. At the same time, biomasses contain less $\mathrm{S}$ and $\mathrm{N}$. $\mathrm{CO}_{2}$, a by-product of combustion can be completely consumed by photosynthesis of green plants again. Therefore, biomass is a kind of clean energy, which can be used to meet the requirement of sustainable development [2]. The total biomass biomass energy resources in China were approximately $7 \times 10^{8}$ tons standard coal. Because of its significant agricultural production, China is rich in crop straw resources. The annual output of crop stalks in China was $6.4 \times 10^{8}$, of which about

\footnotetext{
* Corresponding author at: Key Laboratory of Coal Science and Technology, Ministry of Education and Shanxi Province, Taiyuan University of Technology, Taiyuan, 030024, PR China.

E-mail addresses: zhangguojie@tyut.edu.cn, zhgjdoc@126.com (G. Zhang).
}

$1 \times 10^{8}$ tons consisted of corn stalk, most of which was discarded or burned, leading to serious environmental pollution [3]. Therefore, utilization of corn stalk resources is an important research focus, which will facilitate sustainable agricultural development and protection of the environment [3].

The main biomass thermal conversion processes can be achieved in a number of technologies [4-12], such as combustion, gasification, pyrolysis liquefaction and fermentation, each with its specific requirements, advantages and disadvantages. Pyrolysis of biomass is the most basic process in the process of thermal chemical conversion, gas, liquid and solid materials can be obtained through this process [13-15]. The analysis of pyrolysis is helpful to the control of the thermal chemical conversion process and the development of the process [16]. Thermogravimetric (TG) analysis has been frequently used as a surrogate for the conditions of fast pyrolysis [17]. The TG curve can indicate the weight loss state of the pyrolysis process, and the derivative thermogravimetry (DTG) curve can show the change of the reaction rate with time or temperature. With the thermogravimetric data, the kinetic study could be performed. It allowed this information to be obtained in a simple and straightforward manner. In the literature, numerous works describe TG analysis and behaviors of different materi- 
Table 1

The proximate and ultimate analyses of com stalk.

\begin{tabular}{|c|c|c|c|c|c|c|c|c|c|}
\hline \multirow{2}{*}{$\begin{array}{l}\text { Samples } \\
\text { Cornstalks }\end{array}$} & \multicolumn{4}{|c|}{ Proximate analysis (wt.\%) } & \multicolumn{5}{|c|}{ Ultimate analysis (wt.\%, dry basis) } \\
\hline & Moisture & Volatile & Fixed carbon & Ash & $\mathrm{C}$ & $\mathrm{H}$ & $\mathrm{O}^{\mathrm{a}}$ & $\mathrm{N}$ & $\mathrm{S}$ \\
\hline & 8.14 & 77.14 & 11.09 & 3.63 & 44.72 & 5.57 & 45.01 & 0.92 & 0.15 \\
\hline
\end{tabular}

a Calculate by difference method.

als during thermal degradation [18-24]. He et al. [25] proposed a first-order parallel kinetic model and determined the kinetic parameters (activation energy $E=15 \mathrm{~kJ} / \mathrm{mol}$. Hui et al. [26] had made the thermogravimetric analysis of the pyrolysis behavior of corn stalks; they calculated the activation energy of corn stalks through Popescu, FWO and KAS method. The kinetic analysis shows that the anti-Jander equation is the best most probable mechanism function and the activation energy has an increasing trend with the increase in the heating rate. Kumar et al. [27] investigated the thermal decomposition of corn stoves by TGA and found that there are three distinct stages of weight loss in both condition and kinetic parameters were similar only at slow heating rates. The second stage occurred very rapidly at higher heating rates. Previous reviews on the thermochemical conversion of biomass have dealt with many aspects to promote the amount of combustible components at home and abroad. Li et al. [28] have studied biomass gasification in a pilot fixed and suffer type gasifier using the air and oxygen and steam as the gasification medium respectively, and found that the gas quality is good when the flammable component in the material is high; the flammable component in the gas is increased when the gasification temperature is increased; the calorific power is lower when using air as the gasification medium; the gas component is changed correspondingly when the flux of the gasification medium is changed. The addition of catalysts changed the yields of different gas of fresh corn and wheat straw pyrolysis gasification distributing [29], and increasing the yields of $\mathrm{H}_{2}$. Zinc chloride can restrain producing of $\mathrm{CH}_{4}$; calcium oxide can improve producing of $\mathrm{CH}_{4}$. With the increasing catalysts weight/biomass weight ratio, the yield of $\mathrm{H}_{2}$ increases. Gao et al. have carried out the study of biomass gasification in different operation conditions in an updraft gasifier combined with a porous ceramic reformer, and found that the porous ceramic filled in reformer lead to an increase in the hydrogen production; the conversion ratio of total organic carbon (TOC) contents is between $71.1 \%$ and $75.7 \%$. The conversion of corn stalks into char, oils and gas products using pyrolysis and gasification technologies are the most promising alternatives to convert corn stalk into useful products and energy [10,23].

Studying the pyrolysis characteristics and reaction kinetics parameters of corn stalks, it will provide useful reference data for the operation of the equipment of pyrolysis, vaporization and combustion. The literature data on pyrolysis modeling and kinetics cannot anticipate precisely enough the yield and distribution of pyrolysis products. The objective of the present work is to gain a comprehensive understanding of corn stalk pyrolysis with focus mainly on the distribution and properties of gas products under varied temperatures and pressures, thus facilitating the establishment of a reaction kinetics model to simulate corn stalk pyrolysis and contribute to a better understanding of the processes and mechanism of corn stalk pyrolysis and characteristics of gasification. For this purpose, pyrolysis of actual corn stalk was investigated in a high-pressure reactor at different temperatures and pressures, and the releasing profile and characteristics of the obtained products were thoroughly identified using various approaches. Then the effect of temperature and heating rate on the pyrolysis of corn stalk was performed by the method of thermal analysis at several linear heating rates. The pyrolysis kinetic parameters were determined by the assumption of the pyrolysis kinetics model and the parameters of the corn stalk pyrolysis process.
Table 2

The proximate analysis of char and char yield.

\begin{tabular}{lllll}
\hline \multirow{2}{*}{ Sample } & \multicolumn{2}{l}{ Proximate analysis (wt\%), ad } & \multirow{2}{*}{ Char yield, $700^{\circ} \mathrm{C}$} \\
\cline { 2 - 4 } & Moisture & Ash & Volatile & \\
\hline 40 g corn stalk & 1.67 & 11.26 & 8.77 & 30.2 \\
50 g corn stalk & 1.38 & 12.05 & 8.06 & 31.7 \\
\hline
\end{tabular}

\section{Experimental}

\subsection{Materials}

Corn stalk used in this work was obtained from Taiyuan, Shanxi Province, China, and milled to pass through a 40 sizes screen. The contents of $\mathrm{C}, \mathrm{H}, \mathrm{N}$ and $\mathrm{S}$ were determined using an elemental analyzer (Vario EL, Elementar, Germany). Proximate and ultimate analyses of the corn stalk are shown in Table 1. From the proximate analysis, the biomass has higher content of volatile, which is the main weight loss part in the pyrolysis process. Proximate analysis of char and char yield are shown in Table 2.

\subsection{Experimental}

The thermogravimetric experiments were performed using thermogravimetric analyzer NETZSCH STA 409C. High purity nitrogen was used as the load gas with a $400 \mathrm{ml} / \mathrm{min}$ flow. Thermogravimetric analysis for dehydration step had a heating rate of $10^{\circ} \mathrm{C} / \mathrm{min}^{-1}$, while de-volatilization step were performed at three different heating rates: 5,25 and $35^{\circ} \mathrm{C} / \mathrm{min}$. The samples were milled and sieved, and the selected particle size fraction was in the range of $0-0.2 \mathrm{~mm}$. The weight of corn stalks the feed used during pyrolysis is about $2 \mathrm{mg}$. Prior to the thermogravimetric experiments, the corn stalks were dried in an oven at $105^{\circ} \mathrm{C}$ for $3 \mathrm{~h}$. Each TGA experiment was normalized by the initial dry sample mass. For this purpose, the sample mass measured at $120^{\circ} \mathrm{C}$ was selected. The sample mass normalized in this way is denoted by $\mathrm{m}(\mathrm{t})$. The sample was put in a ceramic crucible heated from room temperature to $800^{\circ} \mathrm{C}$. During the heating, the mass of the corn stalks and furnace temperature were recorded.

Pyrolysis was performed with a high-pressure reactor and a high- temperatures reactor. The high-pressure reactor mainly consists of a stainless steel reactor of volume 0.31 (WHF, Weihai, Shandong). The design working pressure is $30 \mathrm{Mpa}$, and the working temperature is $350^{\circ} \mathrm{C}$. The high-temperatures apparatus (MJF, Beijing, China) mainly consists of a stainless steel cylindrical reactor of height $640 \mathrm{~mm}$, I.D. $140 \mathrm{~mm}$. The design working temperature is $1400^{\circ} \mathrm{C}$.

High-pressure pyrolysis reaction: About $40 \mathrm{~g}$ or $50 \mathrm{~g}$ of corn stalk feed used during pyrolysis was added to the high-pressure fixedbed reactor, and then Nitrogen (99.99\%) was fed into the reactor with a flow rate of $100 \mathrm{ml} / \mathrm{min}$, and oxygen in the reactor was purged until its concentration declined below $0.01 \%$ (by gas chromatography). Subsequently, the reactor was heated to the desired pyrolysis temperature. After the desired temperature was reached and maintained stable $30 \mathrm{~min}$. Pyrolysis experiments were carried out at a heating rate of $2^{\circ} \mathrm{C} / \mathrm{min}$ and at temperature of $330^{\circ} \mathrm{C}$. The amounts of the gases and char fractions were directly calculated. The gas products were analyzed by a gas chromatograph. 


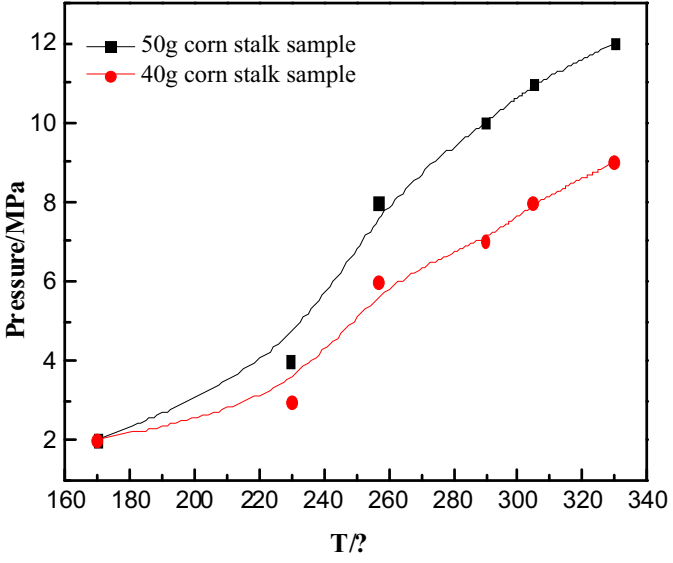

Fig. 1. Influence of temperature on pressure.

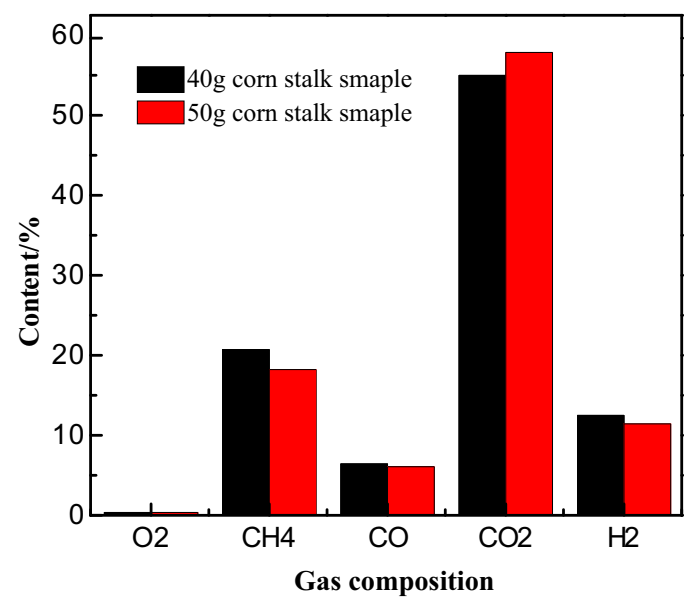

Fig. 2. Gas releasing profile of corn stalk pyrolysis at high pressure reactor.

For each pyrolysis condition, at least two sets of experiments were performed.

High-temperature pyrolysis and gasification at an atmospheric pressure: About $100 \mathrm{~g}$ of corn stalk sample was added to the hightemperature fixed-bed reactor, and Nitrogen (99.99\%) was first fed into the reactor with a flow rate of $100 \mathrm{ml} / \mathrm{min}$ until oxygen concentration declined below $0.01 \%$. Subsequently, the reactor was heated to the desired pyrolysis temperature $\left(200^{\circ} \mathrm{C}, 350^{\circ} \mathrm{C}, 500^{\circ} \mathrm{C}\right.$ and $700^{\circ} \mathrm{C}$ ). Experiments were carried out at a heating rate of $10^{\circ} \mathrm{C} / \mathrm{min}$. The gas products were analyzed by gas chromatograph and volume measured by displacement method. At $700^{\circ} \mathrm{C}$, steam was fed into the reactor with a flow rate of $600 \mathrm{ml} / \mathrm{min}$. Subsequently, the reactor was heated to the desired pyrolysis temperature $\left(750^{\circ} \mathrm{C}, 800^{\circ} \mathrm{C}\right.$, $850^{\circ} \mathrm{C}$ and $900^{\circ} \mathrm{C}$ ). At $900^{\circ} \mathrm{C}$, the electrically heated tubular furnace was switched off when no gas discharged. During the experiment, the gaseous products were analyzed per $50^{\circ} \mathrm{C}$. Gas calorific value calculation formula $H_{\mathrm{m}}$ is as follows:

$H_{\mathrm{m}}=35994 \times \mathrm{CH}_{4} \%+10819 \times \mathrm{H}_{2} \%+12676 \times \mathrm{CO} \%\left(\mathrm{~kJ} / \mathrm{M}^{3}\right)$

Where $\mathrm{CH}_{4} \%, \mathrm{H}_{2} \%$ and $\mathrm{CO} \%$ were the average content of the product of methane gas, hydrogen and carbon monoxide.

Gas yield (V/L) calculation formula is as follows: $\mathrm{V} / \mathrm{L}=\mathrm{Gas}$ volume in different temperature/Total gas volume of the whole temperature range

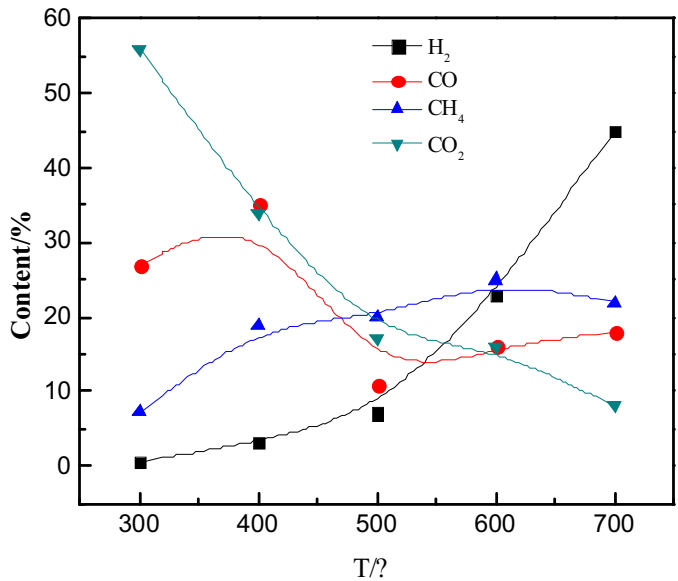

Fig. 3. Gas releasing profile of corn stalk pyrolysis at high temperature reactor.

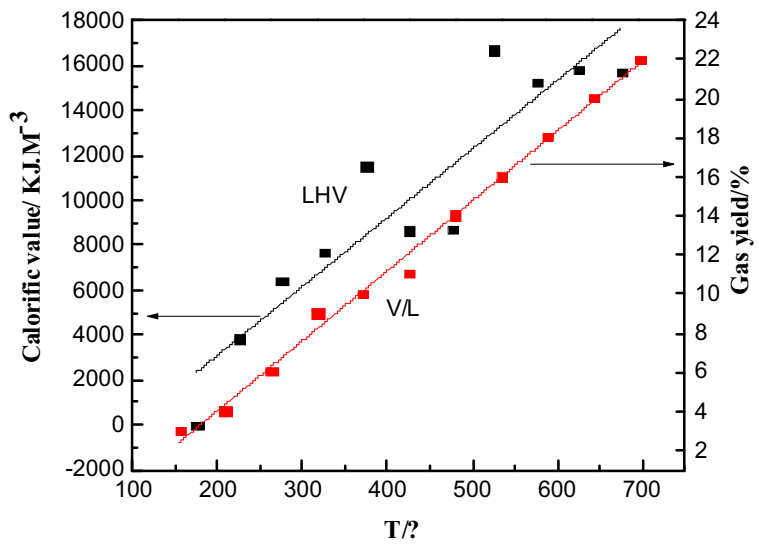

Fig. 4. Influence of temperature on gas production LHV and gas yield.

\subsection{Product analysis}

Gas products of pyrolysis and gasification were analyzed using gas chromatography. GC-950 gas chromatograph equipped a thermal conductivity detector (GC-TCD, Haixin, Shanghai) used the column of carbon molecular sieve column which filled with the monomer of GDX-303. The carrier gas is high-purity hydrogen (hydrogen-table pressure $0.20 \mathrm{MPa}$, pre-column pressure $0.04 \mathrm{MPa}$, and bridge flow $100 \mathrm{~mA}$ ) and detector temperature is $40^{\circ} \mathrm{C}$. GC9890A gas chromatograph equipped thermal conductivity detector (GC-TCD, Linghua, Shanghai) used the column of carbon molecular sieve column which filled with the monomer of GDX-303. The carrier gas is high-purity nitrogen (nitrogen-table pressure $0.30 \mathrm{MPa}$, pre-column pressure $0.10 \mathrm{MPa}$ ) and detector temperature is $80^{\circ} \mathrm{C}$. Elemental analysis of the corn stalk was determined using an elemental analyzer (Vario, ELEMENTAR, Germany).

\subsection{Kinetic methods}

As is well-known to everyone, corn stalk consists mainly of three major components: hemicellulose, cellulose, and lignin [31,32]. Due to their physical and chemical structure, the pyrolysis process of the corn stalk includes many serial and parallel chemical processes, which lead to complex reaction. The establishment of dynamics should be carried out under certain assumptions and the reaction kinetics of the corn stalk should be the following basic hypothesis $[24,33]$. 


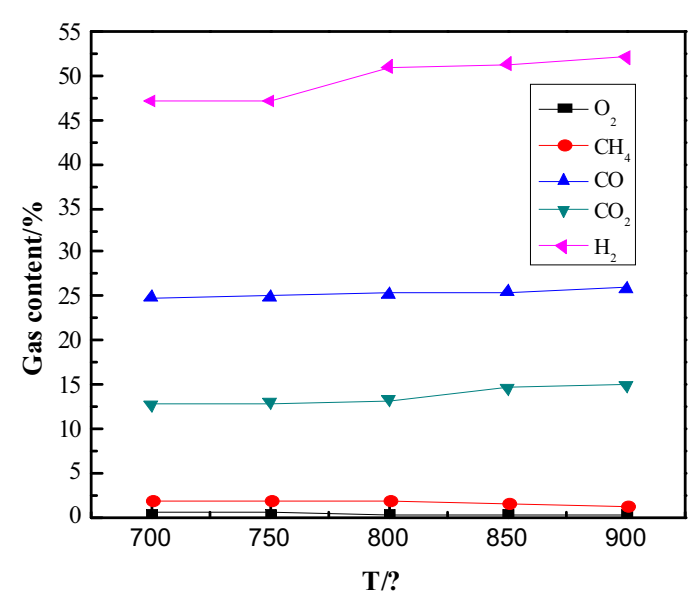

Fig. 5. Gas compositions of gasification pyrolytic char.

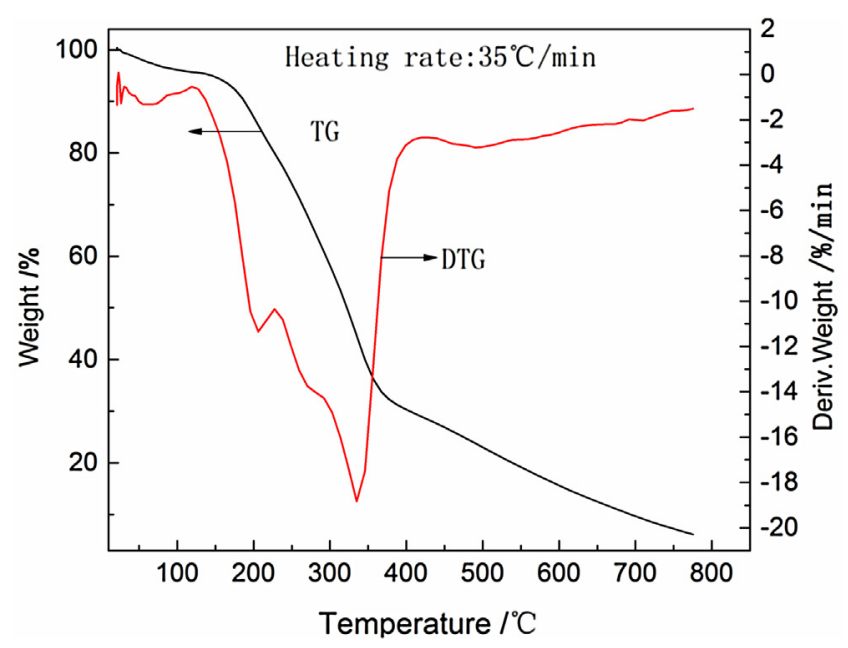

Fig. 6. DTG and TG curves of a corn stalk in nitrogen at $35^{\circ} \mathrm{C} / \mathrm{min}$ heating rates.

(1) The type of pyrolysis reaction is:

$\mathrm{A}($ solid $) \rightarrow \mathrm{B}($ solid $)+\mathrm{C}($ gas $)$

(2) The pyrolysis atmosphere has no effect on the pyrolysis of corn stalk.

(3) There was no temperature gradient during the pyrolysis reaction of corn stalk.

(4) Arrhenius equation can be used for pyrolysis of formula (1), the kinetics of reactions in solid-state are described by the following equation [33]:

$\frac{d \alpha}{d t}=k f(a)$

where $\alpha$ is the degree of conversion of the reaction in time

$\alpha=\frac{m_{0-m_{t}}}{m_{0}-m_{e}}$

where $m_{0}, m_{e}$, and $m_{t}$ are the sample weight at the start and the end of every section, and at time $t$, respectively; $k$ is the reaction rate constant; $f(\alpha)$ is the mechanism function, which generally obeys the Arrhenius equation.

$k(T)=A \exp (-E / R T)$

where $A$ is the pre-exponential factor, $E$ is the activation energy, $T$ is the absolute temperature, and $\mathrm{R}$ is the gas constant.
Function $f(\alpha)$ depends on mechanism of reaction and type of reaction. When first order or second order, $f(\alpha)$ can be was described by

$f(\alpha)=(1-\alpha)^{n}$

Where $n$ is reaction order. Combination of the three reaction Eqs. (2)-(4) gives the fundamental expression (6) of analytical methods to calculate kinetic parameters, on the basis of TGA results.

$\frac{d a}{d t}=A e^{-\left(\frac{E}{R T}\right)}(1-a)^{n}$

For non-isothermal, TGA experiments at the constant heating rate could be described as $\phi=\frac{d a}{d T}$, the Eq. (6) could be described as follows:

$\frac{d a}{d T}=\left(\frac{A}{\phi}\right) e^{-\left(\frac{E}{R T}\right)}(1-a)^{n}$

This equation expresses the fraction of material consumed in the time. In this paper the activation energy was obtained from nonisothermal TGA. The methods used to calculate kinetic parameters are called model-free non-isothermal methods and require a set of experimental tests at different heating rates.

\section{Results and discussion}

\section{1. characteristics of corn stalk pyrolysis}

\subsubsection{Characteristics of corn stalk high-pressure pyrolysis}

For the sealed high-pressure reactor, when the pyrolysis temperature increases, the pressure can be caused by the reaction of corn stalk pyrolysis to syngas remained in the reactor. Plotting the pressure $(\mathrm{P})$ against the absolute temperature was shown in Fig. 1.

It can be seen form Fig. 1 that the pyrolysis temperature had a positive impact on the formation of gas products (pressure), and the reaction final pressure increased with increasing corn stalk weight; that is, the pressure tended to increase as the final pyrolysis temperature increased from 170 to $330^{\circ} \mathrm{C}$ and reached its maximum value $(12 \mathrm{MPa})$ at $330^{\circ} \mathrm{C}$. Clearly, the increase in the pressure in the temperature range of $170-230^{\circ} \mathrm{C}$ was not as fast as that in the range of $230-330^{\circ} \mathrm{C}$. The results obtained from the thermal decomposition process indicate that the high-pressure pyrolysis process of the corn stalk includes three steps: dehydration, pyrolysis and secondary pyrolysis. From room temperature to $330^{\circ} \mathrm{C}$, the reaction pressure gradually increased with increasing pyrolysis temperature mainly for two reasons: moisture content in the raw material removed to form water vapor; on the other hand, the unstable branched chain of cellulose, hemicellulose and lignin macromolecule heated to form volatile gases. The second stage (pyrolysis stage), from $230^{\circ} \mathrm{C}$ to $260^{\circ} \mathrm{C}$, pressure quickly increased with increasing pyrolysis temperature. At this stage, the macromolecular structure such as cellulose, hemicellulose and its derivatives is damaged, $\mathrm{C}-\mathrm{O}$ bonds of between $\mathrm{D}$-glucose unit and $\mathrm{C}-\mathrm{O}$ bonds, $\mathrm{C}-\mathrm{C}$ bonds and a small number of $\mathrm{C}-\mathrm{H}, \mathrm{C}-\mathrm{OH}$ bond of D-glucose ruptured to form a large number of medium and small molecular compounds. Small molecular compounds precipitated in gaseous form, and middle molecular compounds precipitated in gaseous form and liquid form. So pressure increased rapidly with a large number of gaseous product precipitates. The third stage (secondary pyrolysis), from $260^{\circ} \mathrm{C}$ to $330^{\circ} \mathrm{C}$, pressure slowly increased with increasing pyrolysis temperature. The main reason is that the big and medium molecular species formed in the pyrolysis stage further were pyrolyzed, internal bonds among medium and large molecules were broken. In this stage, the bonds cracking were more difficult than the second stage, so the pyrolysis rate is lower than the pyrolysis stage, and the corresponding rise rate of react pressure decreases. 
The main gas products from the pyrolysis process were $\mathrm{CO}_{2}, \mathrm{CO}$, $\mathrm{H}_{2}$ and $\mathrm{CH}_{4}$. The gas products in $330^{\circ} \mathrm{C}$ was shown in Fig. 2. As can be observed from Fig. 2, the releasing profile of gas showed a similar pattern under different pressure, the amount of $\mathrm{CH}_{4}, \mathrm{CO}_{2}$, $\mathrm{CO}$ and $\mathrm{H}_{2}$ accounted for $18,56,6$ and $11 \%$, respectively. Compared with $1 \% \mathrm{H}_{2}$ and $25 \% \mathrm{CO}$ in gas production of high-temperature corn stalk pyrolysis at an atmospheric pressure, the composition of $\mathrm{CO}$ decreased and the composition of $\mathrm{H}_{2}$ increased. It indicated that the pressure inhibited the generation of $\mathrm{CO}$ and was beneficial to generate $\mathrm{H}_{2}$ and $\mathrm{CH}_{4}$. The calorific value of the gas products was about $8860.6 \mathrm{~kJ} / \mathrm{M}^{3}$. It can be seen that the $\mathrm{CO}_{2}$ production was significantly higher than that of other gases. This is because there are a large number of acetyl groups originating from uronic acid in the structure of hemicellulose, which undergo a decarboxylation reaction during pyrolysis, and thus release large amounts of $\mathrm{CO}_{2}$ [10].

\subsubsection{Characteristics of corn stalk high-temperature pyrolysis}

Fig. 3 showed the influence of temperature on gas releasing profile of corn stalk pyrolysis at a high temperature reactor. It can be observed that the $\mathrm{CO}_{2}$ content decreased significantly from $56 \%$ to $8 \%$ as temperature increased from $300^{\circ} \mathrm{C}$ to $700^{\circ} \mathrm{C}$, and $\mathrm{CH}_{4}$, $\mathrm{H}_{2}$ content significantly increased. It indicated that gas products of pyrolysis can occur secondary reaction under high-temperature. Over the whole temperature range analyzed, CO content increased slightly with increasing temperature, then, as the temperature further increased, CO content basically remained unchanged. It is consistent with the previous results reported [34]. They proposed that the formation of $\mathrm{CO}$ is due to secondary cracking of tars. Over the whole temperature range, the releasing content of $\mathrm{CH}_{4}$ increased slightly with increasing temperature and reached a maximum yield of $25 \%$ at $600{ }^{\circ} \mathrm{C} . \mathrm{H}_{2}$ showed a similar pattern with that of $\mathrm{CH}_{4}$. However, its increasing rate was much higher after $500^{\circ} \mathrm{C}$, and the maximum content of $45 \%$ at $700{ }^{\circ} \mathrm{C}$ was higher than that of $\mathrm{CH}_{4}$. It can be concluded that $\mathrm{H}_{2}$ production from corn stalk pyrolysis is mainly dependent on the secondary reactions of volatiles, especially in the high temperature range. The $\mathrm{CH}_{4}$ started to evolve at temperature $>300^{\circ} \mathrm{C}$ because of the cracking of methoxyl functions, and then it increased as temperature increase.

Influence of temperature on gas yield $(\mathrm{V} / \mathrm{L})$ and calorific value (LHV) was shown in Fig. 4. It can be seen from Fig. 4 that the pyrolysis temperatures had a major impact on the gas yield and calorific value. As it also can be seen from Fig. 4, gas yield increased gradually with temperature increasing. It is due to that the relatively poor stability components of tar further broke up and generated small molecule gaseous components with increasing temperature, resulting in gas yields increasing. According to the views of Wei [35], the extent of secondary reactions is affected by reactor temperature and vapor residence time in the reactor. The calorific value of produced gas showed a similar pattern with that of gas yield.

\subsubsection{Characteristics of gasification of pyrolytic char of corn stalk}

From Table 2 can be seen, about 30\% char was produced after corn stalk pyrolysis under $700^{\circ} \mathrm{C}$. The temperature of gasification has important influence on the proportion of combustible gas components and gasification intensity [36,37]. A typical profile of gas composition of gasification pyrolytic char with temperature increasing is plotted in Fig. 5.

The main chemical reaction of the biomass char gasification was represented as follows [33].

$$
\begin{aligned}
& 2 \mathrm{C}+\mathrm{O}_{2}=2 \mathrm{CO}_{2}+394 \mathrm{~kJ} \\
& \mathrm{C}+\mathrm{CO}_{2}=2 \mathrm{CO}-172 \mathrm{~kJ} \\
& \mathrm{H}_{2} \mathrm{O}+\mathrm{CO}=\mathrm{CO}_{2}+\mathrm{H}_{2}-2.89 \mathrm{~kJ}
\end{aligned}
$$

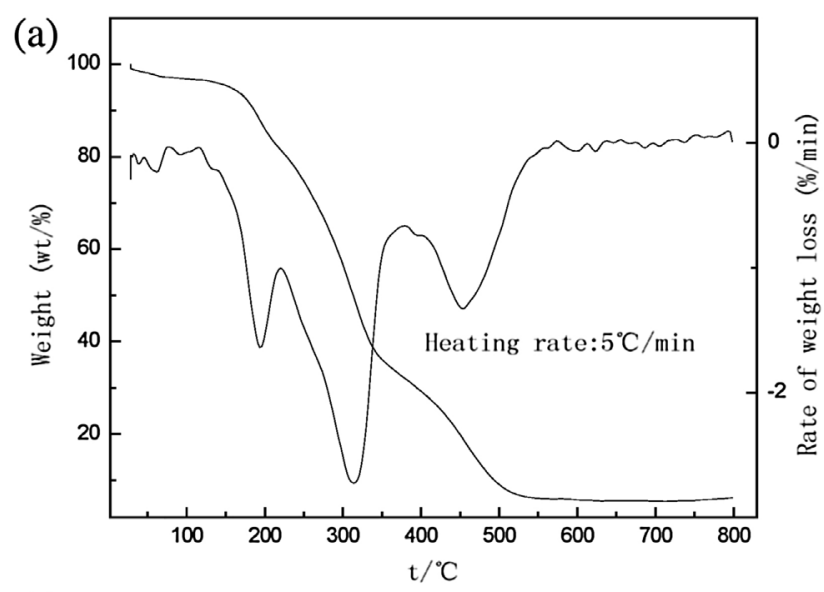

(b)
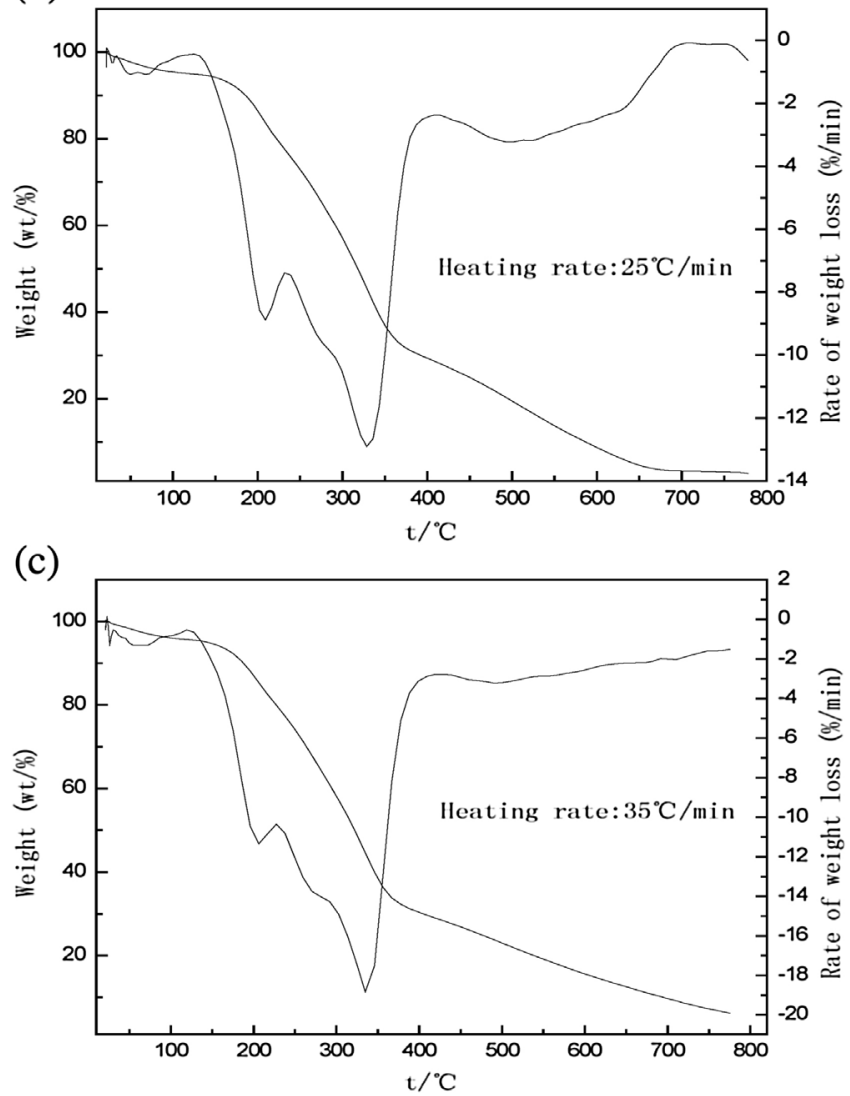

Fig. 7. Weight loss TG and DTG curves of corn stalk at different heating rates.

$\mathrm{C}+\mathrm{H}_{2} \mathrm{O}=\mathrm{CO}+\mathrm{H}_{2}-175 \mathrm{~kJ}$

$\mathrm{C}+2 \mathrm{H}_{2}=\mathrm{CH}_{4}+75 \mathrm{~kJ}$

As seen from Fig. 5, the content of $\mathrm{H}_{2}$ increased slightly with increasing temperature. $\mathrm{CO}_{2}$ and $\mathrm{CO}$ showed a similar pattern with that of $\mathrm{H}_{2}$. But the content of $\mathrm{CH}_{4}$ decreased slightly with increasing temperature. It indicated that pyrolytic carbon had good reaction with steam. According to the reaction equations above, the adding of steam increased the reaction rates of Eqs. (9)-(11) when sufficient heat was provided. The reaction rates of Eqs. (10) and (11) were faster than Eq. (9) with increasing temperature, with the adding of steam in the system. Then the result is that the content of $\mathrm{H}, \mathrm{CO}$ and $\mathrm{CO}_{2}$ slightly increased and the amount of $\mathrm{CH}_{4}$ slightly decreased. The rate of $\mathrm{H}_{2} / \mathrm{CO}$ in the gas products of gasification was 


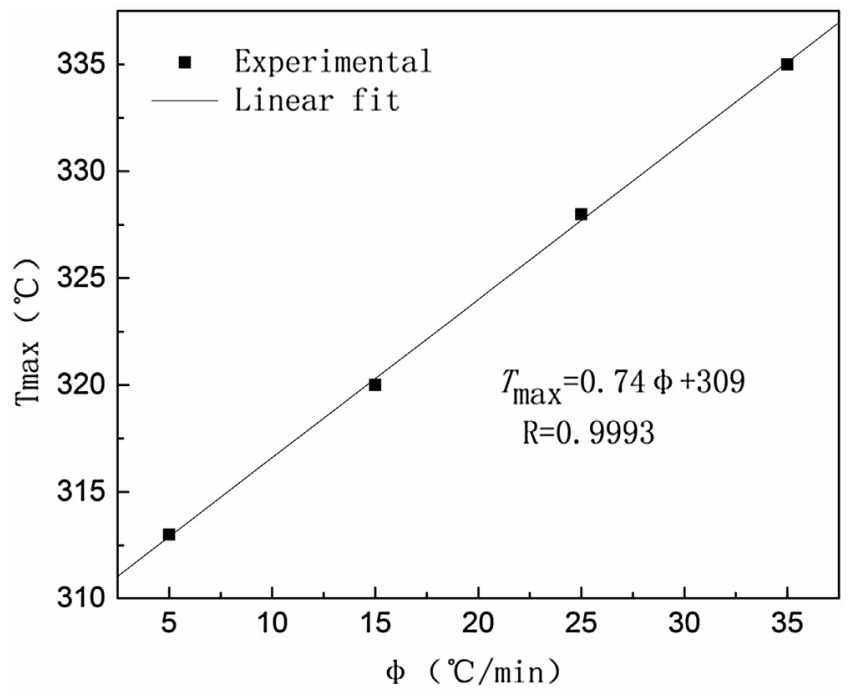

Fig. 8. Relationship of $T_{\max }$ and $\varphi$ for comstalk pyrolysis.

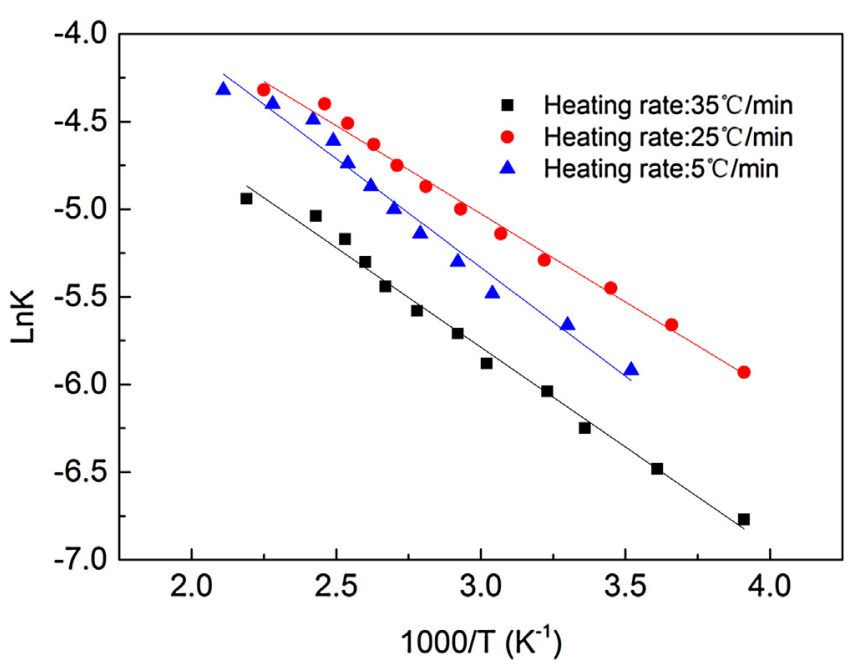

Fig. 9. Relationship between $\ln K$ and $1 / \mathrm{T}$ at different heating rates.

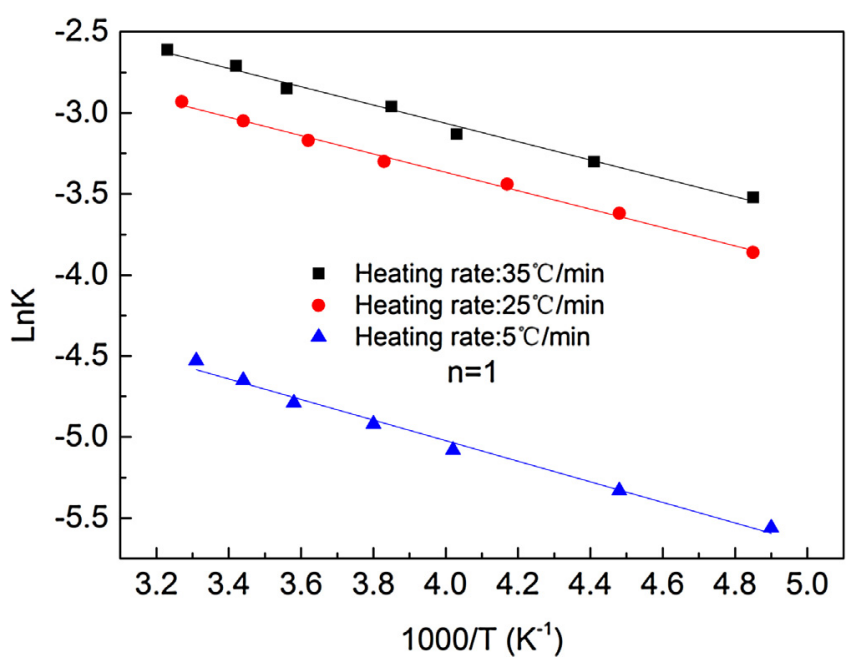

Fig. 10. Relationship between $\ln K$ and $1 / \mathrm{T}$ at different heating rates.
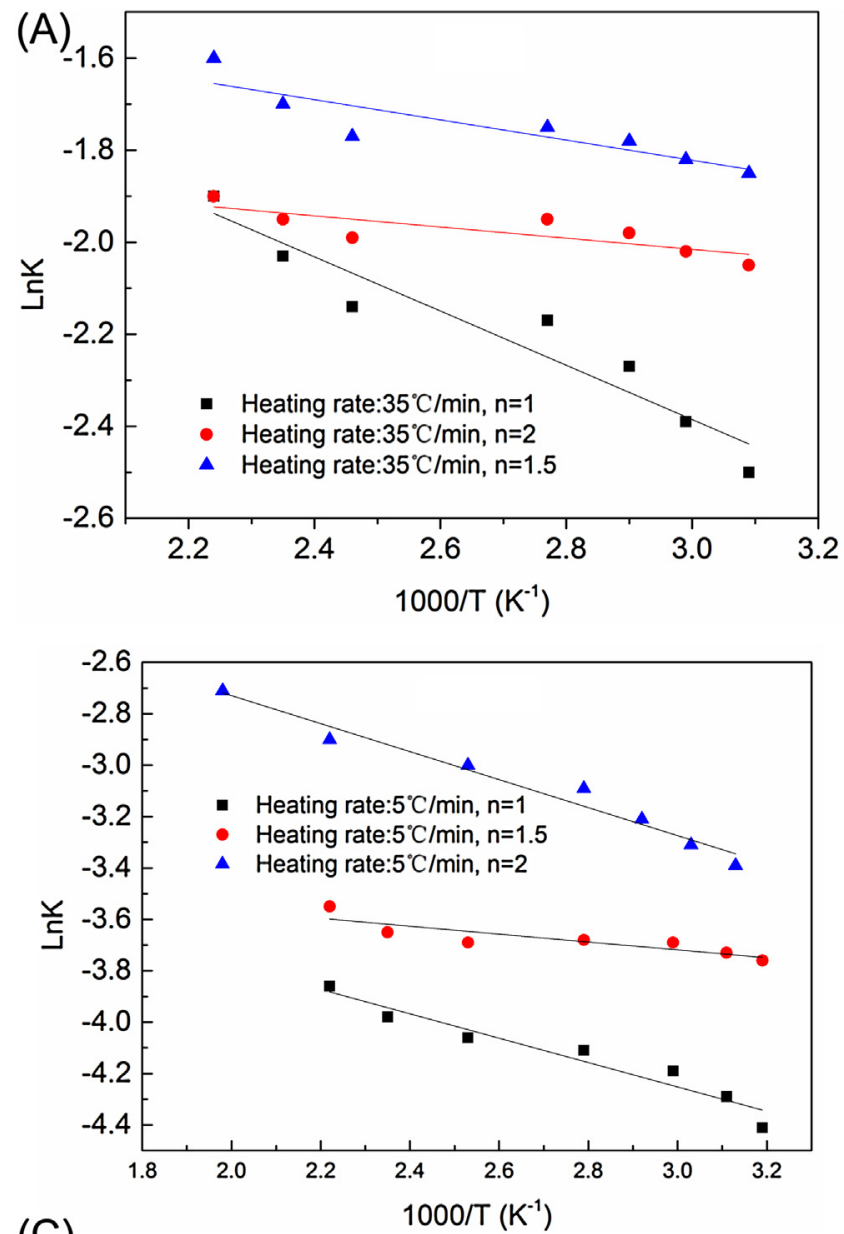

(C)

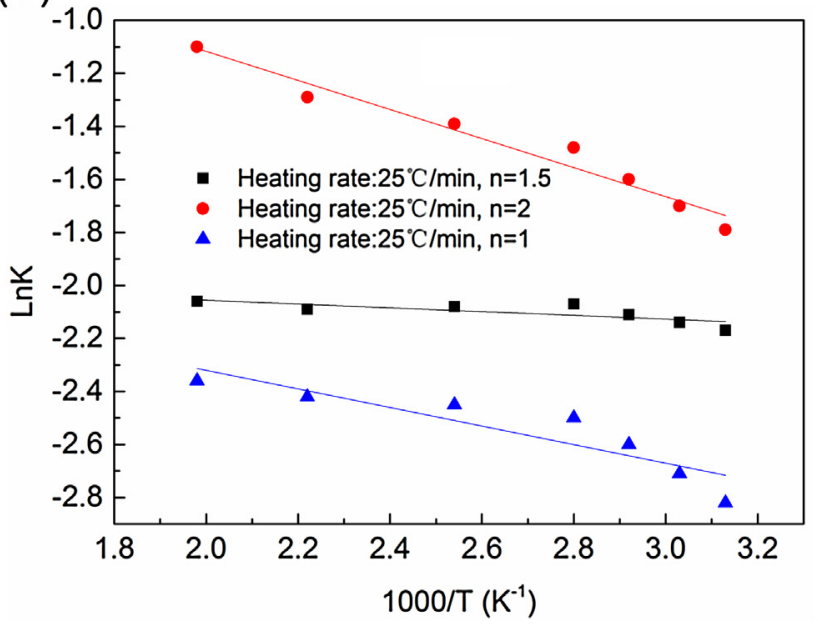

Fig. 11. Relationship between $\ln K$ and $1 / T$ at different heating rates and reaction order $n$.

about 2.0, which is available for the FT synthesis. The calorific value of syngas was about $9508.90 \mathrm{~kJ} / \mathrm{M}^{3}$.

\subsection{Thermogravimetric analysis}

\subsubsection{The effect of temperature on the corn stalk pyrolysis}

Temperature is one of the most prominent factors in the pyrolysis of material. Thus, it is important to study the influence of temperature on the pyrolysis of the corn stalk. The mass loss thermograms of thermal decomposition of the corn stalk pyrolysis, at heating rates $35^{\circ} \mathrm{C} / \mathrm{min}$ under nitrogen atmosphere, are 
shown in Fig. 6. The weight loss of corn stalk in the pyrolysis process is caused by gas evolution. It could be found from Fig. 1 that the pyrolysis process of the corn stalk can be divided into 3 stages. They are correspond to dehydration $\left(20^{\circ} \mathrm{C}-150^{\circ} \mathrm{C}\right)$, mainpyrolysis $\left(150^{\circ} \mathrm{C}-400^{\circ} \mathrm{C}\right)$ and carbonization. The first stage from $20^{\circ} \mathrm{C}$ to $150^{\circ} \mathrm{C}$ is related to the extraction of moisture and adsorbed water in the corn stalk sample. At the same time, because of the hemicellulose plays a connection role between lignin and cellulose, and its chemical stability is poor, so a small hemicellulose started to decompose slowly [28-31]. The second stage is the main thermal decomposition of the corn stalk, the DTG curve also dramatically changed this paragraph. As can be seen from the plot, a little devolatilization process occurs at about $150^{\circ} \mathrm{C}$ and proceeds rapidly with increasing temperature until about $400^{\circ} \mathrm{C}$ and then the weight loss decreases slowly to the final temperature. With the temperature increasing, the weight loss rate of sample increased, the reaction rate is accelerated, with the maximum loss rate of obtained at about $310^{\circ} \mathrm{C}$, corresponding to a peak value on the DTG diagram. In this region, about $80 \%$ to $85 \%$ of the total weight loss, there are two peaks which the literature $[30,31,38-40]$ shows to be related to hemicellulose and cellulose decomposition, while lignin is decomposed in both regions of main-pyrolysis and carbonization without characteristic peaks. The third stage $\left(\geq 400^{\circ} \mathrm{C}\right)$ is the slow decomposition of residues (carbonization stage), and the generation of ash and fixed carbon at last. In this stage, the loss of weight is smaller than the second stage, the solid residue yields are about $5 \%$ for corn stalk.

\subsubsection{The effect of heating rate on the pyrolysis of corn stalk}

Differential mass loss thermograms curves of thermal decomposition of corn stalk pyrolysis, at three heating rates $5,25,35^{\circ} \mathrm{C} / \mathrm{min}$ under nitrogen atmosphere, are shown in Fig. 7. All tested samples are found to follow similar trends on the curves. Heating rates affect TG curve positions, maximum decomposition rate and location of maximum $T_{\max }$ peaks. It can be seen from Fig. 7, along with the increase of heating rate, starting and final temperature of the mainpyrolysis and carbonization region also increase. The TG curve at different heating rates is very similar. Maximum points of TG and minimum points of DTG curves move forward to high temperature, due to thermal lag effect. This data are coherent with the literature [31]. In the case of achieving the same weight loss, with the increase of heating rate, the required temperature for pyrolysis has increased. Under the same temperature, the lower the heating rate, the pyrolysis is more sufficient, the volatile precipitation is more. Based on heat transfer limitation, at low heating rate, a larger instantaneous thermal energy is provided in the system and a longer time may be required for the purge gas to reach equilibrium with the temperature of the furnace or the sample. Then the pyrolysis time is long, the conversion will be improved. While at the same time and in the same temperature region, higher heating rate has a short reaction time and the temperature needed for the sample to decompose is also higher. The increase of heating rate makes the temperature difference between inside and outside larger, the products of pyrolysis from the outer particle have no time to spread, and it will affect the conduct of the internal pyrolysis. This causes the maximum rate curve to shift to the side of high temperature [40].

From the figure of DTG-TG curves and related calculations, it can obtain the parameters of the pyrolysis characteristics: (1) The max pyrolysis rate $\left(\% /{ }^{\circ} \mathrm{C}\right) ;(2)$ Temperature of the highest volatilization rate $\mathrm{T}_{\max }\left({ }^{\circ} \mathrm{C}\right) ;(3)$ The maximum weight loss rate the required time. Table 3 lists the main characteristic parameters of corn stalks at four heating rates $5^{\circ} \mathrm{C}, 15^{\circ} \mathrm{C}, 25^{\circ} \mathrm{C}, 35^{\circ} \mathrm{C}$ /min under nitrogen atmosphere. The relationship between the maximum weight loss
Table 3

Maximum pyrolysis rate and corresponding temperature at different heating rates.

\begin{tabular}{llll}
\hline $\begin{array}{l}\text { Heating rates } \\
\left({ }^{\circ} \mathrm{C} / \mathrm{min}\right)\end{array}$ & $\begin{array}{l}\text { Maximum } \\
\text { Pyrolysis rate } \\
\left(\% /{ }^{\circ} \mathrm{C}\right)\end{array}$ & $T_{\max }\left({ }^{\circ} \mathrm{C}\right)$ & $\begin{array}{l}\text { Pyrolysis Time } \\
(\mathrm{min} .)\end{array}$ \\
\hline 5 & -2.7244 & 313 & 63 \\
15 & -10.5218 & 320 & 22 \\
25 & -12.9040 & 328 & 16 \\
35 & -18.8226 & 335 & 10 \\
\hline
\end{tabular}

Table 4

Kinetic results of corn stalk pyrolysis.

\begin{tabular}{lllll}
\hline $\begin{array}{l}\text { Heating rates } \\
\left({ }^{\circ} \mathrm{C} / \mathrm{min}\right)\end{array}$ & Temperature $\left({ }^{\circ} \mathrm{C}\right)$ & $E(\mathrm{KJ} / \mathrm{mol})$ & $\ln A\left(\mathrm{~min}^{-1}\right)$ & $\mathrm{R}$ \\
\hline 5 & & & & \\
25 & $204-395$ & 26.1 & 1.3 & -0.979 \\
35 & $206-394$ & 25.3 & 1.7 & -0.992 \\
\hline
\end{tabular}

rate Temperature $T_{\max }$ and the corresponding different heating rate $\Phi$ are shown in Fig. 8.

\subsection{The corn stalk pyrolysis kinetic analysis}

\subsubsection{The determination of first-order kinetics parameters}

According to the basic hypothesis, pyrolysis of the corn stalk is a simple reaction; the process of reaction does not involve parallel reaction and consecutive reaction. So the process of reaction could be described by first order reaction model. This data is coherent with the literature [31].

In the above Eq. (7), when $n=1$, integrating the function of Eq. (7) over temperature T leads to Eq. (13):

$\int \frac{d a}{-a}=\int\left(\frac{k}{\phi}\right) d T$

$-\ln (1-\alpha)=\mathrm{k} / \phi \times \mathrm{T}$

Substituting the different $\alpha$ and T into the Eq. (14) yielded different k, putting different k into the Eq. (3) would get the Arrhenius equation. Taking the log of both sides of the equation, it would get the Eq. (15).

$\ln \mathrm{k}=-\mathrm{E} /(\mathrm{RT})+\ln \mathrm{A}$

$-\frac{E}{R T}$ is the slope of the straight line and $\ln A$ is the intercept. Plotting the curve of $\ln \mathrm{k}$ versus $1 / \mathrm{T}$ leads to the slope that can be applied to activation energy $E$ and pre-exponential factor $A$, respectively.

In the study of corn stalk pyrolysis kinetics, researchers are concerned with the characteristics of the main pyrolysis region. So, apparent kinetic model is established to obtain the pyrolysis kinetic parameters in this stage. In order to eliminate effects of moisture and ash content to kinetics of the results, the weight loss ratio $\alpha$ is about $15 \%-70 \%$. When $\alpha$ is $\geq 15 \%$, the moisture of corn stalk is close to 0 ; when $\alpha$ is $\leq 75 \%$, the main precipitate is volatile.

Fig. 9 is the relationship between $\ln \mathrm{k}$ and $1 / T$ at different heating rates $5^{\circ} \mathrm{C}, 25^{\circ} \mathrm{C}, 35^{\circ} \mathrm{C} / \mathrm{min}$. It could be found that the liner fitting degree is high; the pyrolysis reaction of corn stalks can be described with the first-order kinetics model in their main reaction temperatures. The kinetic parameters results of corn stalk pyrolysis obtained are given in Table 4.

It can be seen from Fig. 9 that the relationship between $\ln \mathrm{k}$ and $1 / \mathrm{T}$ is a straight line with Tends to zero intercept in low temperature area. But there is any deviation in the high temperature area. This is because the pyrolysis process can be described by a one-step reaction at a low temperature. At a low temperature, the pyrolytic reaction of the corn stalk carried out mainly through the Eq. (1). For high temperature, these can be described by two consecutive reac- 
Table 5

Kinetic results of corn stalk pyrolysis at low temperature.

\begin{tabular}{lllll}
\hline $\begin{array}{l}\text { Heating rates } \\
\left({ }^{\circ} \mathrm{C} / \mathrm{min}\right)\end{array}$ & $\begin{array}{l}\text { Temperature } \\
\left({ }^{\circ} \mathrm{C}\right)\end{array}$ & $E(\mathrm{KJ} / \mathrm{mol})$ & $\ln A\left(\mathrm{~min}^{-1}\right)$ & $\mathrm{R}$ \\
\hline 5 & $204-302$ & 25.5 & 1.2 & -0.996 \\
25 & $206-306$ & 25.3 & 1.7 & -0.998 \\
35 & $204-310$ & 25.3 & 2.0 & -0.998 \\
\hline
\end{tabular}

tions. The secondary reaction of pyrolysis is unavoidable besides the main reaction (1).

Especially, from Table 3, it can be seen when temperature is between $200^{\circ} \mathrm{C}$ and $400^{\circ} \mathrm{C}$, the activation energy of corn stalk pyrolysis is about $25 \mathrm{KJ} / \mathrm{mol}$, the pyrolysis of corn straw is relatively easy. There are two spikes in the curve of corn stalk weight loss rate (DTG) at this temperature. With the heating rate increased, the frequency factor decreased. However, due to the pyrolysis process of three components is quite complicated, the activation energy does not necessarily under different heating rate.

\subsubsection{The determination of two section pyrolysis kinetic parameters}

When the temperature is higher, $\ln \mathrm{k}$ and $1 / T$ linear degree may not give higher accuracy (Fig. 9). This is because that the influence of heating rate on the pyrolysis of the corn stalk is complex. For the same weight loss, the higher the heating rate, the pyrolysis temperature needs the higher. The same temperature, the pyrolysis is more sufficient under the lower the heating rate, and the volatile precipitation is more. It is for that the heating rate affects the temperature difference between internal and outside parts of the sample, and it will affect the conduct of the internal pyrolysis. Under low heating rate, corn stalk remained at a low temperature for a long time, which favored the development of condensed structures. As a result, only few volatile matters are precipitated. Under high heating rate, more corn stalk structures will be decomposed. This will enhance precipitation of volatile matters.

In order to describe the process of corn stalk pyrolysis reaction accurately, based on the first order reaction kinetics model, the mechanism of function was determined and two-stage pyrolysis dynamic parameters were obtained. When temperature is higher, the different parameters $(n=1, n=1.5$ and $n=2)$ are introduced into Eq. (7). It was integrated to get the Eqs. (16)-(18). The activation energy $(E)$ and frequency factor $(A)$ could be obtained through the relation between $\ln \mathrm{k}$ and $1 / T$. Substituting the different $\alpha$ and $\mathrm{T}$ into the Eqs. (16)-(18) yielded different $k$, putting different $K$ into the Eq. (15) get the relationship between $\ln \mathrm{k}$ and $1 / \mathrm{T}$. Then Reaction activation energy $E$ and frequency $A$ were obtained.

$-\ln (1-\alpha)=\mathrm{k} / \phi \times \mathrm{T}(\mathrm{n}=1$, shrinkingcoremodel $)$

$\frac{1}{\sqrt{(1-a)}}=\left(\frac{k}{\phi}\right) T$

$$
\frac{1}{(1-a)}-1=\left(\frac{k}{\phi}\right) T \quad(\mathrm{n}=2, \text { chemical reaction model })(
$$

It can be easily demonstrated that the cut-off point between low temperature and high temperature zone is in the temperature range of the maximum weight loss rate. Fig. 10 is the relationship between $\ln \mathrm{k}$ and $1 / T$ at different heating rates. Table 5 is the kinetic results of corn stalk pyrolysis at different heating rates. It can be seen that it is feasible to describe corn stalk pyrolysis which is before the maximum weight loss rate as first order reaction. The activation energy is about $25 \mathrm{KJ} / \mathrm{mol}$.

Fig. 11 is the relationship between $\ln \mathrm{k}$ and $1 / \mathrm{T}$ at different heating rates and $\mathrm{n}$. The apparent activation energies were obtained from the slope and pre-exponential factors from the intercept of regression line and are given in Table 6 . The calculated squares of the correlation coefficients, R, correspond to linear fittings in Fig. 11, were higher for all cases and were in range from -0.955 to -0.986 . It can be easily founded that the reaction in a high temperature zone is more complicated than in low temperature zone. The results show that the pyrolysis reaction of corn stalks can be described with the second-order kinetics in high temperature. However, due to the pyrolysis process of the components of the corn stalk is complicated; the activation energy does not necessarily under different heating rate.

\section{Conclusion}

In this work, corn stalk pyrolysis and kinetic study was presented. The results show that temperatures and pressures have an important influence on the combustible gas components of product gas. A higher reactor pressure was conducive to the yield of $\mathrm{H}_{2}$ and $\mathrm{CH}_{4}$, and was not conducive to the generation of CO. Combustible gas components increase with the increase reactor temperature. $\mathrm{H}_{2}$ concentration was affected significantly by temperature at room pressure, was mainly released at $>500^{\circ} \mathrm{C}$. At $700^{\circ} \mathrm{C}$, the combustible gas components are up to $90 \%$ and $\mathrm{H}_{2}$ concentration is up to $51.78 \%$. The calorific value of pyrolysis gas is up to $8860.64 \mathrm{~kJ} / \mathrm{M}^{3}$. The gas components of the corn stalk pyrolytic char gasification mainly consisted of $\mathrm{CO}$ and $\mathrm{H}_{2}, 25.69 \%$ and $50.67 \%$ respectively. The rate of $\mathrm{H}_{2} / \mathrm{CO}$ in the gas products of pyrolytic char gasification with steam was about 2 , which is available for the FT synthesis. The calorific value of gasification gas is up to $9508.90 \mathrm{~kJ} / \mathrm{M}^{3}$ at $700-900^{\circ} \mathrm{C}$. By using the Popescu method to determine that the mechanism, at the low temperature pyrolysis, shrinking core model $(n=1)$ can reflect the pyrolysis process of the corn stalk truly, the activation energy obtained is $25 \mathrm{~kJ} / \mathrm{mol}$; at high temperature pyrolysis, chemical reaction model $(n=2)$ can reflect the pyrolysis process of the corn stalk truly, the activation energy obtained is among $16-24 \mathrm{~kJ} / \mathrm{mol}$.

Table 6

Kinetic results of corn stalk Pyrolysis at high temperature.

\begin{tabular}{|c|c|c|c|c|c|}
\hline Heating rates $\left({ }^{\circ} \mathrm{C} / \mathrm{min}\right)$ & Temperature $\left({ }^{\circ} \mathrm{C}\right)$ & n Reaction order & $E(\mathrm{KJ} / \mathrm{mol})$ & $\ln A\left(\min ^{-1}\right)$ & $\mathrm{R}$ \\
\hline \multirow[t]{3}{*}{5} & $313-451$ & 1 & 15.8 & 1.8 & -0.979 \\
\hline & $313-451$ & 1.5 & 7.8 & 2.8 & -0.972 \\
\hline & $313-451$ & 2 & 21.0 & 0.4 & -0.984 \\
\hline \multirow[t]{4}{*}{25} & $319-506$ & 1 & 11.9 & 1.0 & -0.939 \\
\hline & $319-506$ & 1.5 & 5.5 & 1.6 & -0.966 \\
\hline & $319-506$ & 2 & 16.7 & 1.1 & -0.986 \\
\hline & $324-447$ & 1 & 18.3 & 0.7 & -0.971 \\
\hline \multirow[t]{2}{*}{35} & $324-447$ & 1.5 & 9.4 & 0.6 & -0.955 \\
\hline & $324-447$ & 2 & 24.1 & 2.8 & -0.972 \\
\hline
\end{tabular}




\section{Acknowledgements}

This work was supported by the National Natural Science Foundation of China (Grant No. 21676174 and 21376003), National Science \& Technology Pillar Program (Grant No. 2012BAA04B03), the Program for the Outstanding Innovative Teams of Higher Learning Institutions of Shanxi and the Joint Fund of Shanxi Provincial Coal Seam Gas (2015012019).

\section{References}

[1] F. Demirbas, M. Balat, H. Balat, Potential contribution of biomass to sustainable energy development, Energy Convers. Manag. 50 (2009) 1746-1760.

[2] F. Lin, C.L. Waters, R.G. Mallinson, L.L. Lobban, L.E. Bartley, Relationships between biomass composition and liquid products formed via pyrolysis, Front. Energy Res. 45 (2015) 1-15.

[3] B. Zhang, H. Zhao, H. Yu, D. Chen, X. Li, W. Wang, R. Piao, Z. Cui, Evaluation of biogas production performance and archaeal microbial dynamics of corn straw during anaerobic co-digestion with cattle manure liquid, J. Microbiol. Biotechnol. 26 (2016) 739-747.

[4] I.Y. Mohammed, Y.A. Abakr, K.F. Kabir, S. Yusuf, I. Alshareef, A.C. Soh, Pyrolysis of oil palm residues in a fixed bed tubular reactor, J. Power Energy Eng. 3 (2015) 185-193.

[5] A. Saidur, E. Abdelaziz, A. Demirbas, M. Hossain, S. Mekhilef, A review on biomass as a fuel for boilers, Renew. Sustain. Energy Rev. 15 (2010) 2262-2289.

[6] A. Demirbas, Potential applications of renewable energy sources, biomas combustion problems in boiler power systems and combustion related environmental issues, Prog. Energy Combust. Sci. 31 (2005) 171-192.

[7] A.S. Al-Rahbi, J.A. Onwudili, P.T. Williams, Thermal decomposition and gasification of biomass pyrolysis gases using a hot bed of waste derived pyrolysis char, Bioresour. Technol. 204 (2016) 71-79.

[8] P. Ranganathan, S. Gu, Computational fluid dynamics modelling of biomass fast pyrolysis in fluidised bed reactors, focusing different kinetic schemes, Bioresour. Technol. 213 (2016) 333-341.

[9] D. Klinar, Universal model of slow pyrolysis technology producing biochar and heat from standard biomass needed for the techno-economic assessment, Bioresour. Technol. 206 (2016) 112-120.

[10] G. Lv, S. Wu, R. Lou, Charcteristics of corn stalk hemicellulose pyrolysis in a tubular reactor, Bioresour. Technol. 5 (2010) 2051-2062.

[11] D. Mohan, C.U. Pittman Jr., P.H. Steele, Pyrolysis of wood/biomass for bio-oil: a critical review, Energy Fuels 20 (2006) 848-889.

[12] M.G. Perez, A. Chaala, H. Pakdel, D. Kretschmer, C. Roy, Characterization of bio-oils in chemical families, Biomass Bioenergy 31 (2007) 222-242.

[13] Z. Li, W. Zhao, B. Meng, C. Liu, Kinetic study of corn straw pyrolysis: comparison of two different three-pseudocomponent models, Bioresour. Technol. 99 (2008) 7616-7622.

[14] S. Sfakiotakis, D. Vamvuka, Development of a modified independent parallel reactions kinetic model and comparison with the distributed activation energy model for the pyrolysis of a wide variety of biomass fuels, Bioresour. Technol. 197 (2015) 434-442.

[15] S. Ceylan, Y. Topcu, Z. Ceylan, Thermal behaviour and kinetics of alga Polysiphonia elongata biomass during pyrolysis, Bioresour. Technol. 171 (2014) 193-198.

[16] M. Lanzetta, C.D. Blasi, Pyrolysis kinetics of wheat and corn straw, J. Anal. Appl. Pyrolysis 44 (1997) 181-192.
[17] P.R. Pstwardhan, D.L. Dalluge, B.H. Shanks, Distinguishing primary and secondary reactions of cellulose pyrolysis, Bioresour. Technol. 102 (2011) 5265-5269.

[18] A.E.S. Green, J. Feng, Systematics of corn stover pyrolysis yields and comparisons of analytical and kinetic representations, J. Anal. Appl. Pyrolysis 76 (2006) 60-69.

[19] P.R. Patwardhan, P.A. Johnston, R.C. Brown, B.H. Shanks, Understanding fast pyrolysis of lignin, Prepr. Am. Chem. Soc. Div. Pet. Chem. 55 (2010) 104-105

[20] J. Wu, S. Gao, J. Wan, Y. Zeng, Thermogravimetric kinetics of corn stalk pretreated by oleaginous fungi cunninghamella echinulata, Bioresour. Technol. 102 (2011) 5255-5258.

[21] Y. Xu, Y. Zhang, G. Zhang, Y. Guo, Low temperature pyrolysates distribution and kinetics of Zhaotong lignite, Energy Convers. Manage. 114 (2016) 11-19.

[22] X. Fu, Z. Zhong, G. Xiao, Comparative study on pyrolysis characteristics and dynamics of grass biomass, Trans CSAE 25 (2009) 199-202.

[23] G. Lv, S. Wu, G. Yang, J. Chen, Comparative study of pyrolysis behaviors of corn stalk and its three components, J. Anal. Appl. Pyrolysis 104 (2013) 185-193.

[24] G. Lv, S. Wu, R. Lou, Kinetic study of thermal decomposition of hemicelluloses isolated from corn stalk, BioResources 5 (2010) 1281-1291.

[25] F. He, W. Yi, R. Sun, Pyrolysis and its kinetics of cornstalk and wheat straw, Trans CSAE 20 (2002) 13-18.

[26] S. Hui, L. Liang, Q. Fan, C. Liu, Z. Chen, Q. Jing, Experimental study and kinetics analysis on pyrolysis characteristics of corn stalk, Therm. Power Gen. 43 (2014) 69-75.

[27] A. Kumar, L. Wang, Y. Dzenis, D. Jones, M. Hanna, Thermogravimetric characterization of corn stover as gasification and pyrolysis feedstock, Biomas Bioenergy 32 (2008) 460-467.

[28] Y. Li, R. Li, A. Li, L. Feng, W. Yao, Experimental study on characteristic of biomass gasification, Power Syst. Eng. 23 (2007) 12-14.

[29] F. Min, M. Zhang, Q. Cheng, M. Chen, Trial study on catalytic pyrolysis gasification of fresh biomass to produce hydrogen rich gas, J. China Coal Soc. 31 (2006) 649-653.

[30] N. Gao, A. Li, C. Quan, A novel reforming method for hydrogen production from biomass steam gasification, Bioresour. Technol. 100 (2009) 4271-4277.

[31] X. Liu, Y. Zhang, Z. Li, R. Feng, Y. Zhang, Characterization of corncob-derived biochar and pyrolysis kinetics in comparison with corn stalk and sawdust, Bioresour. Technol. 170 (2014) 76-82.

[32] F.X. Collard, J. Blin, A review on pyrolysis of biomass constituents: mechanisms and composition of the products obtained from the conversion of cellulose, hemicelluloses and lignin, Renew. Sustain. Energy Rev. 38 (2014) 594-608.

[33] B. Urych, A. Smoliníski, Kinetics of sewage sludge pyrolysis and air gasification of its chars, Energy Fuels 30 (2016) 4869-4878.

[34] S.R. Wang, H. Tan, Z.Y. Luo, Experimental research on rapid pyrolysis of xylan, J. Zhejiang Univ. 40 (2006) 419-423.

[35] L.G. Wei, S.P. Xu, L. Zhang, Characteristics of fast pyrolysis of biomass in a free fall reactor, Fuel Process. Technol. 87 (2006) 863-871.

[36] L. Ma, Biomass Gasification Technology and Its Application, Fourth ed. Chemical Industry Press, Beijing, 2003.

[37] L. Zhao, X. Li, G. Wang, J. Li, D. Zhang, The research and utilization on biomass gasification, Renew. Energy Resour. 26 (2008) 55-58.

[38] L. Gasparovic, Z. Korenova, L. Jelemensky, Kinetic study of wood chips decomposition by TGA, Chem. Pap. 64 (2010) 174-181.

[39] V. Strezov, B. Moghtaderi, J. Lucas, Thermal study of decomposition of selected biomass samples, J. Therm. Anal. Calorim. 72 (2003) 1041-1048.

[40] P.O. Biney, M. Gyamerah, J. Shen, B. Menezes, Kinetics of the pyrolysis of arundo sawdust, corn stover and switch grass biomass by thermogravimetric analysis using a multi-stage model, Bioresour. Technol. 179 (2015) 113-122. 